\title{
Economic applications of quantile regression 2.0
}

\author{
Bernd Fitzenberger ${ }^{1} \cdot$ Roger Koenker $^{2} \cdot$ José Machado $^{3} \cdot$ Blaise Melly $^{4}$ \\ Published online: 24 December 2021 \\ (c) The Author(s) 2021
}

Twenty years ago, Empirical Economics was instrumental in supporting a conference at the University of Konstanz on economic applications of quantile regression that attracted a number of influential research papers that were subsequently published by the journal (see Fitzenberger et al. 2001), and later reprinted in a volume published by Physica-Verlag. Quantile regression has continued to flourish throughout applied economics since then, and in June of 2019, a second conference was held at the new campus of the Nova School of Business and Economics in Portugal. Again, the papers covered a broad span of topics in applied economics, some of which have been collected in this special issue of Empirical Economics. The editors wish to express their thanks to the authors and to the journal for its support over this period, and hope that the collection of these new papers will encourage the continued development and application of these methods into the future.

This special issue of Empirical Economics combines eight empirical applications of quantile regression and related methods focusing on modeling distributional heterogeneity in outcomes. Two papers extend the applicability of quantile regression methods regarding computational improvements and multivariate responses. Making use of methodological developments over the last 2 decades, the scope of

\footnotetext{
$\bowtie \quad$ Bernd Fitzenberger

bernd.fitzenberger@fau.de

Roger Koenker

r.koenker@ucl.ac.uk

José Machado

jafm@novasbe.pt

Blaise Melly

blaise.melly@vwi.unibe.ch

1 Institute for Employment Research (IAB) and Friedrich-Alexander-Universität Erlangen-Nürnberg (FAU), Nürnberg, Berlin, Germany

2 University College London, London, UK

3 Universidade NOVA de Lisboa, Lisbon, Portugal

4 University of Bern, Bern, Switzerland
} 
quantile regression methods has been expanded tremendously into new areas such as panel regression analysis, endogeneity, selection, or group-level heterogeneity, some of which Koenker (2005) at the time attributed to the twilight zone of quantile regression-where there is more light today than 20 years ago. The empirical applications in economics cluster in empirical finance, labor economics with overlap into environmental economics, personnel economics, and behavioral economics, thus showing the broad applicability of quantile regression to generate novel substantive insights in economics.

\section{Fast algorithms for the quantile regression process}

Chernozhukov et al. (2022) describe several new methods for speeding up quantile regression computations when it is desirable to estimate a large number of distinct quantiles. Given an initial solution, solutions at nearly adjacent quantiles can exploit preprocessing ideas introduced in Portnoy and Koenker (1997). This approach can also be adapted to bootstrapping and in large samples substantially reduces the computational burden. Implementations of the new methods have been made available in both Stata and R.

\section{Vector quantile regression and optimal transport, from theory to numerics}

Carlier et al. (2022) describe a new approach to multivariate quantile regression modeling-based recent developments in optimal transportation. After a careful exposition of the univariate case that reveals the close connections to the classical Monge-Kantorovich theory and conventional conditional quantile estimation, the link to vector quantiles and vector conditional quantiles is developed with the aid of the fundamental results of Brenier, and related earlier work of the authors.

\section{Impact of asset size on performance and outreach using panel quantile regression with non-additive fixed effects}

Kendo and Tchakounte (2022) focus on the impact of asset size on financial performance and outreach for microfinance institutions (MFIs). The empirical analysis applies a panel quantile approach with non-additive fixed effects that helps to organize the microfinance sample into subgroups with similar performance levels. The results reveal that an increase in asset size leads to increased profitability, with a greater impact for MFIs that have poor or low-end profitability levels than for those with satisfactory levels. Regarding outreach, an increase in asset size positively impacts the average loan and the number of active borrowers, but reduces the percentage of female borrowers in the client portfolio. An increase in asset size reduces the percentage of female borrowers more for MFIs that target women less. Conversely, for MFIs that already have a high level of female borrowers, an increase in asset size reduces the 
percentage of female borrowers less. In other words, increasing asset size drives out female borrowers from the client portfolio, an effect that is greater for MFIs targeting fewer female borrowers.

\section{Modelling systemic risk using neural network quantile regression}

Keilbar and Wang (2022) propose a novel approach to estimating conditional Valueat-Risk (CoVaR) across major financial institutions based on neural network quantile regression. The recent financial crisis of 2008/2009 revealed a need for more accurate tail risk measurement and risk management for both financial and non-financial institutions. As the nature of these risks may not necessarily be linear, these machine learning methods may be helpful in improving systemic risk assessment. Methodologically, the paper proposes three alternative measures of systemic risk based on the fitted values of the neural network quantile regressions. Empirically, the authors show that only a few major financial institutions generate a significant contribution to systemic risk during the financial crisis of 2008/2009.

\section{Selection with group structure: a competing risks quantile regression analysis}

Shi and Wilke (2022) consider the problem of modeling retirement decisions in the competing risk quantile regression framework of Peng and Fine (2009). Duration modeling, or survival analysis, has been an actively developing topic within the quantile regression literature since the 2001 conference. Competing risk models are particularly challenging since they involve inherent sample selection issues.

\section{Distributional differences in the time horizon of executive compensation}

Haylock (2022) analyze how the time horizon of compensation plans affects the distribution of executive compensation. They rely on a recent proposal of Machado and Santos Silva (2019) who suggest a computationally convenient method-of-moment approach to estimation of quantile regression models with fixed effects. The aim of these compensation plans is to incentivize executives to maximize long-term firm value. Past research shows that executives' pay is largely determined by short-term stock performance. This study tests for distributional differences in the time horizon of the performance-pay relation, controlling for executive-firm fixed effects. Short-term and long-term firm and industry performance is estimated using a filter and distributional differences. The findings suggest that the right tail of the conditional total compensation distribution has a more long-term performance-pay relation than the left tail. In contrast, the right tail of the conditional accumulated wealth distribution has more short-term performance-pay relation than the left tail. The findings also suggests 
an asymmetry in the short-term firm performance-pay relation, but it does not vary substantially across the conditional distribution.

\section{Gender differences in wage expectations: the role of biased beliefs}

Briel et al. (2022) analyze gender differences in expected starting salaries along the wage expectations distribution of prospective university students in Germany, using elicited beliefs about both own salaries and salaries for average other students in the same field. Unconditional quantile regression, as introduced in Firpo et al. (2009), are used to estimate the impact of a unit change in covariates for all observations on the quantiles of the unconditional outcome distribution. Unconditional and conditional quantile regressions show 5-15\% lower wage expectations for females. At all quantiles considered, the gender gap is more pronounced in the distribution of expected own salary than in the distribution of wages expected for average other students. The results suggest that biased beliefs about earnings potential relative to others and mean salaries play a major role in explaining the gender gap in wage expectations.

\section{Heterogeneous effects of job displacement on earnings}

Various approaches have been suggested to estimate distributional treatment effects of the outcome using a difference-in-differences approach, see e.g., Athey and Imbens (2006). Azadikhah Jahromi and Callaway (2022) go one step beyond by considering the distribution of the individual treatment effects. They identify the joint distribution of the treated and control outcomes via a rank invariance over time assumption. The individual treatment effects of interest can be represented as functions of several conditional distributions. Thus, in the first step, the authors suggest using quantile regression to estimate these conditional distributions. They apply their estimator to estimate the heterogeneity of the effect of job displacement. They find that displaced workers earn about $157 \$$ per week less, on average, than they would have earned if they had not been displaced. They also find substantial heterogeneity: while $42 \%$ of workers have even higher earnings after displacement, $21 \%$ see their earnings dropping by more than $500 \$$.

\section{Changing selection into full-time work and its effect on wage inequality in Germany}

Fitzenberger and de Lazzer (2022) estimate the effect of selection into full-time employment on wage inequality among males using German administrative records. Quantile regression is generally inconsistent in the presence of non-random sample selection. The traditional control function approach to correct such bias is valid for quantile regression only if the quantile regression slope coefficients are homogeneous, i.e., they do not vary with the quantile index. Huber and Melly (2015) have suggested a test of this restriction. Using this test, Fitzenberger and Lazzer find that it rejects the 
homogeneity assumption, and they suggest a transformation of the response variable to account for heteroscedasticity in the original data. The homogeneity assumption is no longer rejected for the transformed response and the control function approach consistently identifies the conditional distribution. The authors find negative selection into employment both in 1995 and 2010. They also show that over time and fulltime workers have become less heterogeneous suggesting that changing selection into employment does not explain the observed increase in wage inequality.

\section{The impact of air pollution on birthweight: evidence from grouped quantile regression}

Chetverikov et al. (2016) suggest a two-step estimated for endogenous group-level treatments and group-level unobservables combining a quantile regressions in the first stage with an IV-estimator in the second stage. Their IV-estimator accounts for grouplevel endogeneity and group-level unobservables, both of which would bias pooled IV estimation based on the original data. Pons (2022) employs this approach to estimate the effect of pollution on birthweight of infants. She argues that the average effect is not informative if more vulnerable infants are disproportionately more affected. The study focuses on the distributional effect of particulate matter pollution on birthweight. The analysis reveals nonhomogeneous effects, suggesting that pollution disproportionately affects infants in the lower tail of the conditional distribution, whereas average effects suggest only minimal and not economically significant impact of pollution on birthweight.

Funding Open Access funding enabled and organized by Projekt DEAL.

Open Access This article is licensed under a Creative Commons Attribution 4.0 International License, which permits use, sharing, adaptation, distribution and reproduction in any medium or format, as long as you give appropriate credit to the original author(s) and the source, provide a link to the Creative Commons licence, and indicate if changes were made. The images or other third party material in this article are included in the article's Creative Commons licence, unless indicated otherwise in a credit line to the material. If material is not included in the article's Creative Commons licence and your intended use is not permitted by statutory regulation or exceeds the permitted use, you will need to obtain permission directly from the copyright holder. To view a copy of this licence, visit http://creativecommons.org/licenses/by/4.0/.

\section{References}

Athey S, Imbens G (2006) Identification and inference in nonlinear difference-in-differences models. Econometrica 74(2):431-497

Azadikhah Jahromi A, Callaway B (2022) Heterogeneous effects of job displacement on earnings. Empir Econ. https://doi.org/10.1007/s00181-020-01961-w

Briel S, Osikominu A, Pfeifer G, Reutter M, Satlukal S (2022) Gender differences in wage expectations: the role of biased beliefs. Empir Econ. https://doi.org/10.1007/s00181-021-02044-0

Carlier G, Chernozhukov V, De Bie G, Galichon A (2022) Vector quantile regression and optimal transport, from theory to numerics. Empir Econ. https://doi.org/10.1007/s00181-020-01919-y

Chernozhukov D, Fernández-Val I, Melly B (2022) Fast algorithms for the quantile regression process. Empir Econ. https://doi.org/10.1007/s00181-020-01898-0 
Chetverikov D, Larsen B, Palmer C (2016) IV quantile regression for group-level treatments, with an application to the distributional effects of trade. Econometrica 84(2):809-833

Firpo S, Fortin NM, Lemieux T (2009) Unconditional quantile regressions. Econometrica 77(3):953-973

Fitzenberger B, de Lazzer J (2022) Changing selection into full-time work and its effect on wage inequality in Germany. Empir Econ. https://doi.org/10.1007/s00181-021-02098-0

Fitzenberger B, Koenker R, Machado JAF (2001) Special issue on economic applications of quantile regression. Empir Econ 26(1):1-324

Haylock MR (2022) Distributional differences in the time horizon of executive compensation. Empir Econ. https://doi.org/10.1007/s00181-021-02042-2

Huber M, Melly B (2015) A test of the conditional independence assumption in sample selection models. J Appl Econom 30(7):1144-1168

Keilbar G, Wang W (2022) Modelling systemic risk using neural network quantile regression. Empir Econ. https://doi.org/10.1007/s00181-021-02035-1

Kendo S, Tchakounte J (2022) Impact of asset size on performance and outreach using panel quantile regression with non-additive fixed effects. Empir Econ. https://doi.org/10.1007/s00181-021-02057-9

Koenker R (2005) Quantile regression. Cambridge Univ. Press, Cambridge

Machado JAF, Santos Silva J (2019) Quantiles via moments. J Econom 213(1):145-173

Peng L, Fine JP (2009) Competing risks quantile regression. J Am Stat Assoc 104:1440-1453

Pons M (2022) The impact of air pollution on birthweight: evidence from grouped quantile regression. Empir Econ. https://doi.org/10.1007/s00181-021-02048-w

Portnoy S, Koenker R (1997) The Gaussian hare and the Laplacian tortoise: computability of squared-error versus absolute-error estimators. Stat Sci 12(4):279-300

Shi S, Wilke R (2022) Selection with group structure: a competing risks quantile regression analysis. Empir Econ

Publisher's Note Springer Nature remains neutral with regard to jurisdictional claims in published maps and institutional affiliations. 